\title{
Syngas Application to Spark Ignition Engine Working Simulations by Use of Rapid Compression Machine
}

\author{
Eliseu Monteiro, Marc Bellenoue, Julien Sottton and Abel Rouboa
}

Additional information is available at the end of the chapter

http://dx.doi.org/10.5772/48088

\section{Introduction}

It has become more and more urgent to find alternative fuels or alternative sources of energy for transportation systems as reserves of standard fossil fuels are decreasing very rapidly. Therefore it is necessary to find alternative fuels to be used in the standard internal combustion engine to bridge this gap. Biomass is considered as the renewable energy source with the highest potential to contribute to the energy needs of modern society for both the developed and developing economies world-wide [1]. Energy from biomass, based on short rotation forestry and other energy crops, can contribute significantly towards the objectives of the Kyoto Agreement in reducing the greenhouse gases emissions and to the problems related to climate change [2]. The gasification of biomass allows the production of a synthesis gas or "syngas," consisting primarily of $\mathrm{H}_{2}, \mathrm{CO}, \mathrm{CH}_{4}, \mathrm{CO}_{2}$ and $\mathrm{N}_{2}$ [3]. The specific composition depends upon the fuel source and the processing technique. These substantial variations in composition and heating value are among the largest barriers toward their usage.

The main advantage that comes from the use of syngas in SI engines over the conventional liquid, petroleum-based fuels is the potential for increased thermal efficiency [4]. This is attributed to the relatively high compression ratios permitted, usually by converting Diesel engines for gaseous fuel operation in the SI mode [5], since $\mathrm{CO}$ and $\mathrm{CH}_{4}$ are characterized by high anti-knock behavior [6]. On the contrary, the relatively increased end-gas temperature, which the fast flame propagation rate of $\mathrm{H}_{2}$ can produce during combustion and can be responsible for knock onset, is compensated for by the presence of diluents in the fuel $\left(\mathrm{N}_{2}\right.$ and $\mathrm{CO}_{2}$ ). Their effect on combustion is to lower flame speed and so decrease the in-cylinder pressures and temperatures. The moderation of peak gas temperatures during combustion, attributed to this feature, has also a reduction effect on $\mathrm{NO}_{x}$ emissions [8]. Besides, the 
drawback of reduced power output using fuels with relatively low heating values can be partially balanced by turbo-charging the engine. Towards the direction of minimizing this power derating when, for example, syngas with low heating value equal to $4-6 \mathrm{MJ} / \mathrm{Nm}^{3}$ is used instead of natural gas with low heating value of approximately $30 \mathrm{MJ} / \mathrm{Nm}^{3}$, contributes the fact that the syngas stoichiometric air-fuel ratio is about 1.2 compared with the value of 17 for the natural gas case. Thus, the energy content per unit quantity of mixture (air + fuel) inducted to the cylinder is only marginally lower when using syngas, compared with the corresponding natural gas case [9].

In single-cylinder or multi-cylinder engines, it is very difficult to control the combustion, because parameters are coupled with each other under engine operating conditions. For this reason, the use of a rapid compression machine (RCM) allows to elucidate about combustion characteristics and visualize combustion phenomena [10-15].

In this chapter, two typical mixtures of $\mathrm{H}_{2}, \mathrm{CO}, \mathrm{CH}_{4}, \mathrm{CO}_{2}$ and $\mathrm{N}_{2}$ have been considered as representative of the producer gas coming from wood gasification, and its turbulent combustion at engine-like conditions is made in a rapid compression machine designed to simulate the thermodynamic cycle of an engine, particularly compression and expansion strokes, in order to improve current knowledge and provide reference data for modeling and simulation with the objective of its application in stationary energy production systems based on internal combustion engines.

\section{Materials and methods}

\subsection{Syngas}

Gasification is the thermo-chemical conversion of a carbonaceous fuel at high temperatures, involving partial oxidation of the fuel elements. The result of the gasification is a fuel gas the so-called syngas - consisting mainly of carbon monoxide $(\mathrm{CO})$, hydrogen $\left(\mathrm{H}_{2}\right)$, carbon dioxide $\left(\mathrm{CO}_{2}\right)$, water vapor $\left(\mathrm{H}_{2} \mathrm{O}\right)$, methane $\left(\mathrm{CH}_{4}\right)$, nitrogen $\left(\mathrm{N}_{2}\right)$, some hydrocarbons in very low quantity and contaminants, such as carbon particles, tar and ash.

Syngas-air mixtures and methane-air mixture are prepared in bottles by means of partial pressure method, and then the mixture is prepared within the chamber by adding syngas and air at specified partial pressures. The purity of the gases is in all cases at least $99.9 \%$. The typical syngas compositions are shown in the Table 1.

\begin{tabular}{|llcccc|}
\hline Gasifier & $\mathrm{H}_{2}$ & $\mathrm{CO}$ & $\mathrm{CO}_{2}$ & $\mathrm{CH}_{4}$ & $\mathrm{~N}_{2}$ \\
\hline Updraft & 11 & 24 & 9 & 3 & 53 \\
Downdraft & 17 & 21 & 13 & 1 & 48 \\
\hline
\end{tabular}

Table 1. Syngas compositions (\% by volume)

The simplified chemical reaction that expresses the stoichiometric combustion of syngas for syngas typical compositions is [16]: 


$$
\begin{aligned}
& a \mathrm{H}_{2}+b \mathrm{CO}+c \mathrm{CH}_{4}+ d \mathrm{CO}_{2}+e \mathrm{~N}_{2}+\left(\frac{a}{2}+\frac{b}{2}+2 c\right)\left(\mathrm{O}_{2}+3.76 \mathrm{~N}_{2}\right) \rightarrow \\
&(b+c+d) \mathrm{CO}_{2}+(a+2 c) \mathrm{H}_{2} \mathrm{O}+\left[e+3.76\left(\frac{a}{2}+\frac{b}{2}+2 c\right)\right] N_{2}
\end{aligned}
$$

Where $a, b, c, d$, and $e$ are molar coefficients. Five experiments for each mixture and ignition timing were performed in order to assure the good reproducibility of the signals. For single compression the maximum difference between peak pressures is: 1.8 bar for ignition at top dead center (TDC) (70 bar on average, which represents an error of 2.5\%); 0.8 bar for ignition timing at $5.0 \mathrm{~ms}$ before TDC (BTDC) (69.2 bar on average representing an error of $1.1 \%$ ); 0.5 bar for ignition timing at $7.5 \mathrm{~ms}$ BTDC (68.8 bar on average, which represents an error of $0.7 \%)$; 0.5 bar for ignition timing at $12.5 \mathrm{~ms}$ BTDC ( 68.4 bar on average representing an error of $0.7 \%$ ). For compression-expansion the maximum difference between peak pressures is: 0.2 bar for ignition timing at $5 \mathrm{~ms}$ BTDC (30 bar on average representing an error of $0.7 \%$ ); 0.1 bar for ignition timing at $7.5 \mathrm{~ms}$ BTDC (38 bar on average, which represents an error of $0.03 \%)$; 0.8 bar for ignition timing at $12.5 \mathrm{~ms}$ BTDC (47.5 bar on average representing an error of $1.7 \%)$.

\subsubsection{Syngas flammability limits}

The flammability limit is the most widely used index for representing the flammability characteristics of gases. In accordance with generally accepted usage, the flammability limits are known as those regions of fuel-air ratio within which flame propagation can be possible and beyond which flame cannot propagate. And there are two distinct separate flammability limits for the fuel-air mixture, namely, the leanest fuel-limit up to which the flame can propagate is termed as lower flammability limit (LFL), and the richest limit is called as upper flammability limit (UFL).

The purpose of this study is to determine the flammability limits of syngas-air mixtures as guidance for stationary energy production systems. As the conditions in an energy production scenario are different, namely in terms of pressure, some apparatus characteristics referred in the standards described above are not followed. The flammable region obtained will be narrower than the actual flammable region.

In this context, prior to our experimental work, various measurements of the flammable region of syngas-air mixtures with a specific ignition system providing ignition energy of 45 $\mathrm{mJ}$ and initial conditions of $293 \mathrm{~K}$ for temperature and 1.0 bar and 3.0 bar for pressure.

The syngas-air mixtures were prepared within the spherical chamber using two 10L bottles previously prepared with the syngas composition and another with compressed atmospheric air by the partial pressure method. The equivalence ratio was varied in 0.1 steps. The flammability limits using for different initial conditions of pressure is shown in figures 1-2. In the boundaries of the flammable region ten shots were made in order to get the ignition success. 


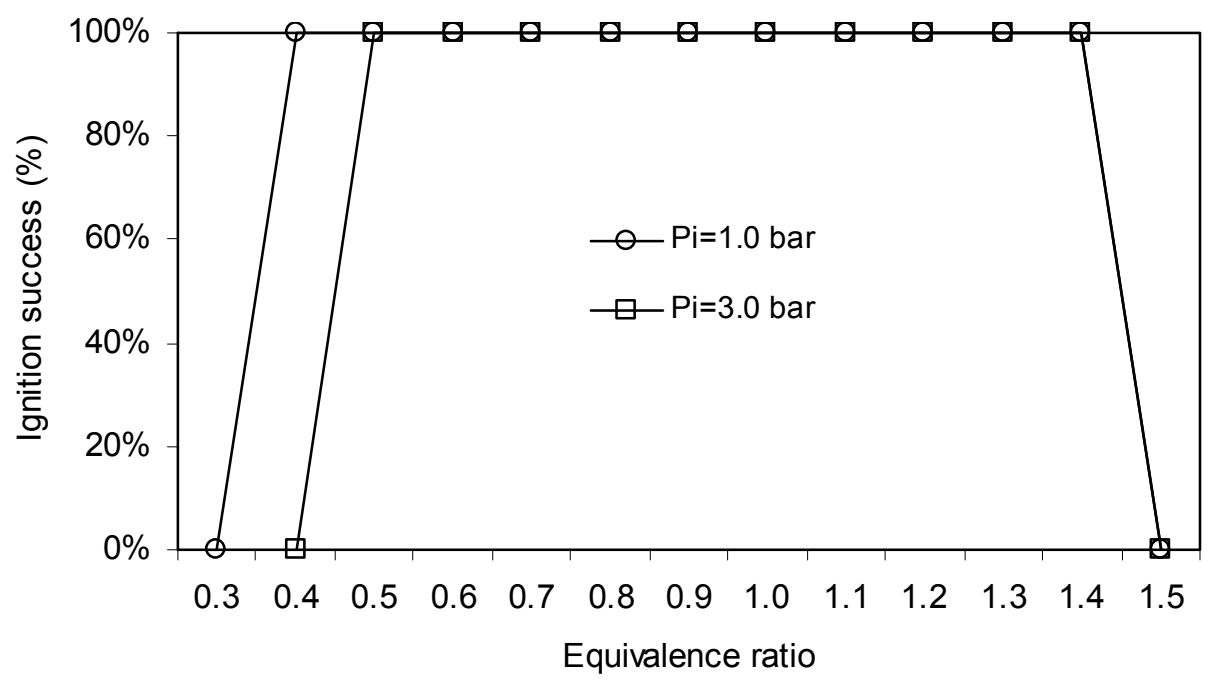

Figure 1. Flammability limits of the updraft syngas-air mixture.

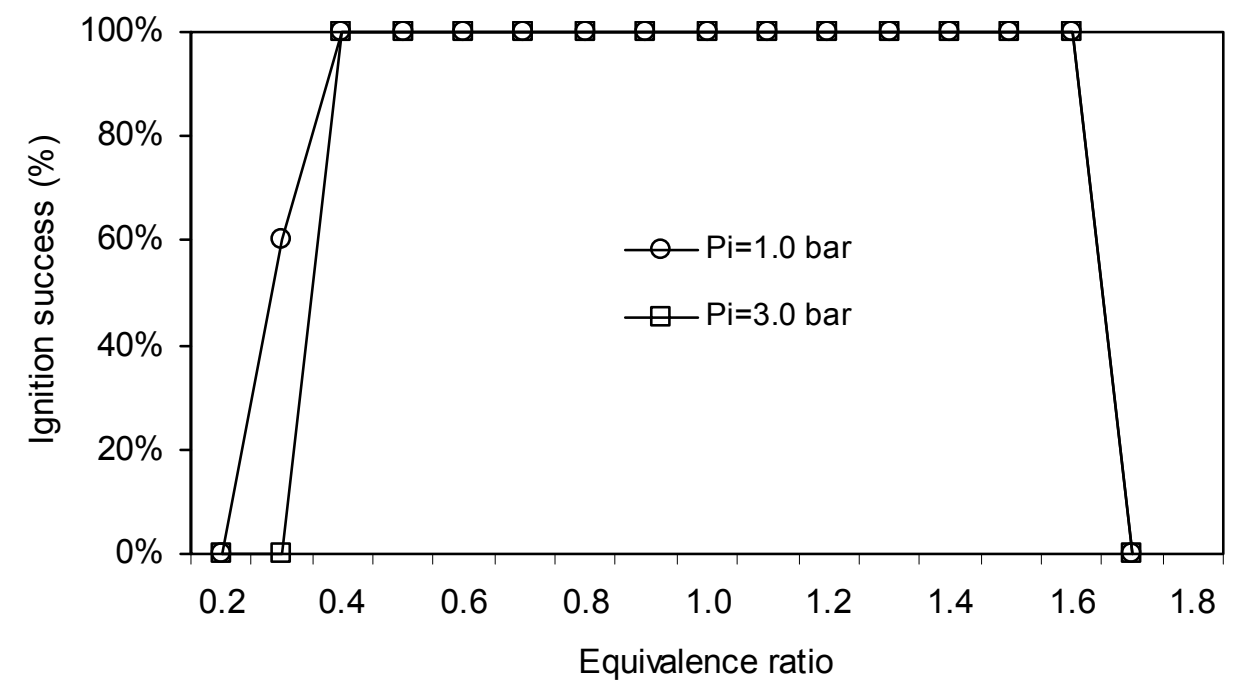

Figure 2. Flammability limits of the downdraft syngas-air mixture.

Figure 1 shows that the flammable region for the updraft syngas-air mixture for 1.0 bar and $293 \mathrm{~K}$ is between 0.4 and 1.4 equivalence ratios. Increasing the initial pressure to $3.0 \mathrm{bar}$, the lean flammability limit is reduced to $\phi=0.5$.

Figure 2 shows that the flammable region for the downdraft syngas-air mixture for 1.0 bar and $293 \mathrm{~K}$ is between 0.3 and 1.6 equivalence ratios. Pressure increase for $\phi=0.3$ is only $20 \%$ of the initial pressure. Increasing the initial pressure to 3.0 bar, the lean flammability limit is reduced to $\phi=0.4$. 


\subsubsection{Burning velocity}

The stretched burning velocity, $S_{u}$, of the propagating flame is calculated by the following expression [17]:

$$
S_{u}=\frac{r_{v}}{3\left(P_{v}-P_{i}\right)}\left(\frac{P_{i}}{P}\right)^{\frac{1}{\gamma}}\left(1-\left(\frac{P_{i}}{P}\right)^{\frac{1}{\gamma}} \frac{P_{v}-P}{P_{v}-P_{i}}\right)^{-\frac{2}{3}} \frac{d P}{d t}
$$

Where $P_{i}$ and $P_{v}$ are the initial and maximum pressure, respectively. $\gamma$ is the specific heat ratio of the mixture and $r_{v}$ is the radius of the combustion chamber.

The simultaneous change in the pressure and temperature of the unburned mixture during a closed vessel explosion makes it necessary to rely on correlations which take these effects into account like the one proposed by [18]:

$$
S_{u}=S_{u_{0}}\left(\frac{T}{T_{0}}\right)^{\alpha}\left(\frac{P}{P_{0}}\right)^{\beta}
$$

Where, $T_{0}$ and $P_{0}$, are the reference temperature and pressure, respectively. $\alpha$ and $\beta$, are temperature and pressure exponents, respectively and $S_{\mathrm{u} 0}$ the reference burning velocity.

The correlations of laminar burning velocities of the typical syngas compositions of the type $S_{u}=S_{u 0}\left(T / T_{0}\right)^{\alpha}\left(P / P_{0}\right)^{\beta}$ under stoichiometric conditions are [16]:

$$
\begin{aligned}
& S_{u}=0.303\left(T / T_{0}\right)^{1.507}\left(P / P_{0}\right)^{-0.259} \\
& S_{u}=0.345\left(T / T_{0}\right)^{1.559}\left(P / P_{0}\right)^{-0.156}
\end{aligned}
$$

where, $T$ is the temperature, $P$ the pressure and the index 0 represents reference conditions (1.0 bar, $293 \mathrm{~K})$.

\subsection{Rapid compression machine}

The experiments were conducted in a rapid compression machine (RCM) at the Institute $\mathrm{P}^{\prime}$ of the ENSMA. This RCM has been designed in such a manner that the piston velocity evolves similarly as it does in a real engine. Volumetric compression ratio of the RCM can be varied from $\varepsilon=9.1$ to $\varepsilon=18.8$ by changing the clearance volume. The RCM features a square cross/section with rounded corners piston $(50 \times 50, \mathrm{r}=3.6 \mathrm{~mm})$, allowing flat windows to be mounted on lateral sides of the chamber; this enables direct visualizations and planar laser sheet measurements within the whole dead volume (Fig. 3).

The piston is equipped with a squared sealing ring but also with a square shaped guiding ring, to avoid asymmetric formation of corner vortex. Moreover the RCM features a long 
compression stroke $(\mathrm{S}=419 \mathrm{~mm})$, providing a wider visualization window at top dead center (TDC) for a given compression ratio. Compression of reactive mixtures is obtained as follows. A hydraulic cylinder sets a cam into motion. The horizontal translation is transformed into a vertical motion via a guiding wheel. The RCM is equipped with a return cylinder to keep the contact between the cam and the guiding wheel; this ensures that the volume of the chamber is well stabilized at TDC.

The RCM is fitted with a heating system in the chamber walls to vary the initial temperature at bottom dead center (BDC) between 293 and $373 \pm 1.5 \mathrm{~K}$.

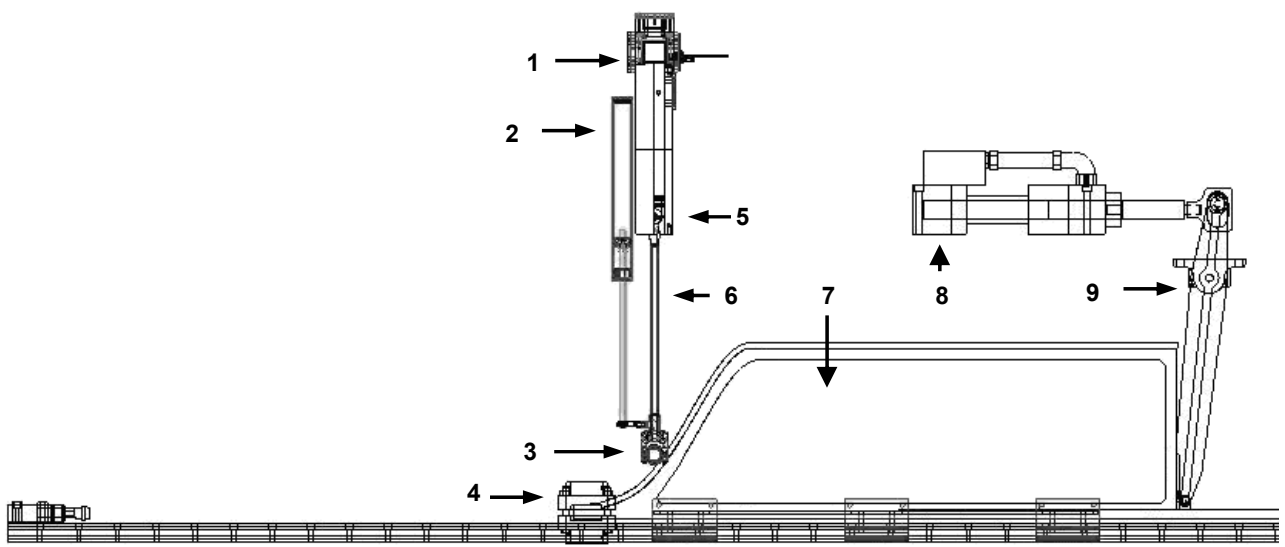

Figure 3. RCM scheme. (1) Cylinder/combustion chamber, (2) return cylinder, (3) guiding wheel, (4) Brake system, (5) Piston, (6) Connecting rod, (7) Cam, (8) hydraulic cylinder, (9) lever.

The mechanical part of the RCM is based on the principle of the catapult. A cylinder, commanded by a high-speed servo valve (response time of approximately $5 \mathrm{~ms}$ ) and supplied with a hydro-electric power station allowing a flow of $400 \mathrm{l} / \mathrm{min}$, drives a steel rod of large dimensions (length $775 \mathrm{~mm}$, thickness $50 \mathrm{~mm}, \mathrm{H}$ section) which in turns drive a carriage of $40 \mathrm{~kg}$ at high speed installed horizontally on rails. This carriage is equipped with a cam whose profile actuates a roller that supports the piston vertical movement. The profile is calculated to reproduce the movement of an engine running at around $700 \mathrm{rpm}$. It was necessary to install hydraulic brakes (ordered in a mechanical way, by safety) on the way of the carriage in order to stop it, which passes from 0 to $40 \mathrm{~km} / \mathrm{h}$ and then from $40 \mathrm{~km} / \mathrm{h}$ to 0 . Everything will take $60 \mathrm{~ms}$, which explains the 5 meters length of the machine.

The RCM is equipped with various measurement means: a laser sensor to measure displacement, inductive sensors positioned along the axis of the piston to start the optical instrumentation and to generate the spark, a sensor to measure the dynamic pressure in the combustion chamber, as well as a thermocouple used during special tests where the chamber is heated, and controlled in temperature. The chamber is equipped with valves intended for the draining and filling of gas mixtures, as well as a secondary cylinder to create controlled aerodynamic effects representative of those found in engines (swirl movement, tumble or homogeneous turbulence). 
The RCM control is managed by a PC. The measuring signs (pressure, piston position, wall temperature, heat flux, etc.) are registered simultaneously by a data acquisition system (National Instrument 6259) and integrated in the interface. Also some RCM controlling parameters (brakes pressure, hydraulic pressure, piston position, contact cam/lever, etc.) are taking into account for security reasons. The interface also controls the signals of the lasers and camera.

In an ideal spark-ignited internal combustion engine one can distingue three stages: compression, combustion and expansion. The entire pressure rise during combustion takes place at constant volume at TDC. However in an actual engine this does not happen as well as in the RCM. The pressure variation due to combustion in a compression and expansion rapid compression machine is shown in figure 4 where three stages of combustion can be distinguished.

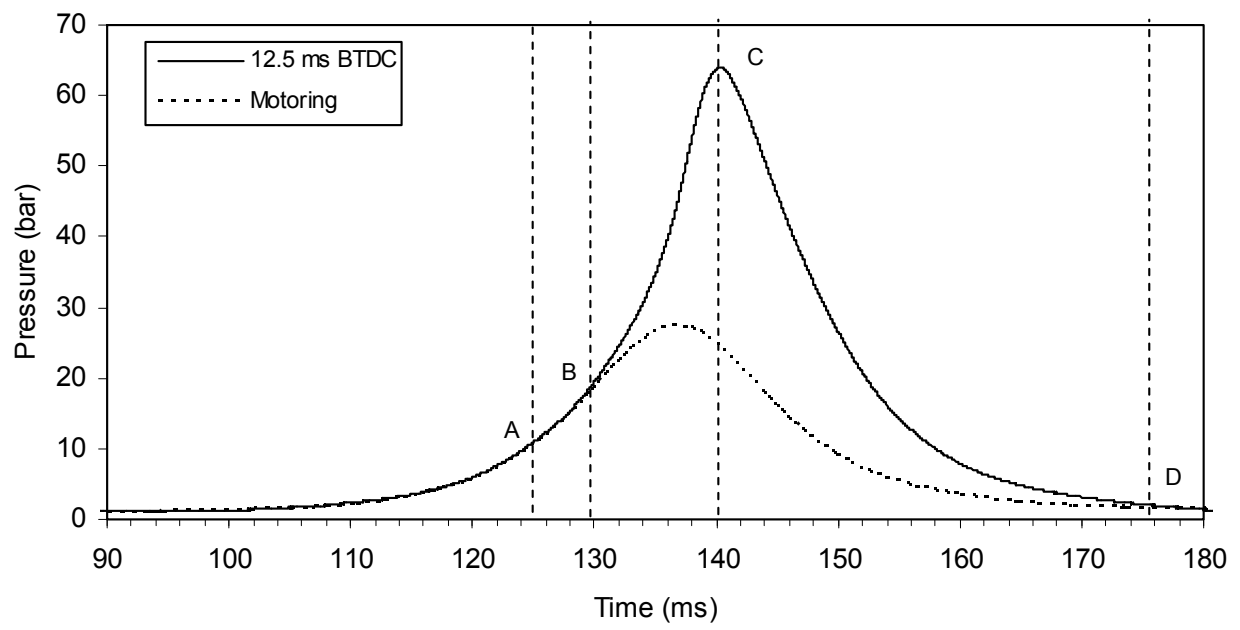

Figure 4. Stages of combustion in a RCM.

In this figure, $\mathrm{A}$ is the point of passage of spark, B is point at which the beginning of pressure rise can be detected and $C$ the attainment of peak pressure. Thus, $A B$ represents the first stage, BC the second stage and CD the third stage [19].

The first stage is referred to as ignition lag or preparation phase in which growth and development of a self-propagating nucleus of flame takes place. This is a chemical process depending upon both pressure and temperature and the nature of the fuel. Further, it is also dependent of the relationship between the temperature and the rate of reaction.

The second stage is a physical one and is concerned with the spread of the flame throughout the combustion chamber. The starting point of the second stage is where the first measurable rise of pressure is seen, i.e. the point where the line of combustion departs from the compression line (point B). This can be seen from the deviation from the compression (motoring) curve.

During the second stage the flame propagates practically at a constant velocity. Heat transfer to the cylinder wall is low, because only a small part of the burning mixture comes 
in contact with the cylinder wall during this period. The rate of heat release depends largely of the turbulence intensity and also of the reaction rate which is dependent on the mixture composition. The rate of pressure rise is proportional to the rate of heat release because during this stage, the combustion chamber volume remains practically constant (since the piston is near the TDC).

The starting point of the third stage is usually taken at the instant at which the maximum pressure is reached (point $\mathrm{C}$ ). The flame velocity decreases during this stage. The rate of combustion becomes low due to lower flame velocity and reduced flame front surface. Since the expansion stroke starts before this stage of combustion, with the piston moving away from the TDC, there can be no pressure rise during this stage.

\subsubsection{Aerodynamics inside the RCM}

Although in principle RCM simulates a single compression event, complex aerodynamic features can affect the state of the reacting core in the reaction chamber. Previous studies [20, 21] have shown that the motion of the piston creates a roll-up vortex, which results in mixing of the cold gas pockets from the boundary layer with the hot gases in the core region. However, substantial discrepancies have been observed between data taken from different rapid compression machines even under similar conditions of temperature and pressure [22]. These discrepancies are attributed partly to the different heat loss characteristics after the end of the compression stroke and partly to the difference in aerodynamics between various machines. The effect of aerodynamics is particularly more complicated because it does not show up in the pressure trace and it may lead to significant temperature gradients and ultimately to the failure of the adiabatic core hypothesis.

The aerodynamics inside a rapid compression machine is highly unsteady in nature; it plays a role in pre-ignition through turbulent mixing, but also because it drives the evolution of the temperature distribution. The characterization of the temporal evolution of the flow, and quantify the distribution and turbulence intensity is made using an inert gas $\mathrm{N}_{2}$ to simplify the diagnosis and avoiding the disruption of PIV images by possible oxidation of unwanted particles. The flow remains representative of the reactive case when the heat release is negligible. Measurements on the total extent of the clearance volume and at the center of the chamber were made.

\subsubsection{Velocity fluctuations}

The study of turbulent flows is generally based on the Reynolds decomposition, where the instantaneous velocity $(\mathrm{U})$ is decomposed into an averaged $(<\mathrm{U}\rangle)$ part and a fluctuating $(\mathrm{u})$ part: $\mathrm{U}=<\mathrm{U}>+\mathrm{u}$.

In most cases, a global average is used to estimate mean velocity. Using this approach in an engine results in substantial overestimation of the turbulent intensity that can reach a factor of 2 [23]. Indeed, the cyclical fluctuations of the overall movement (such as large eddy scale movement) are included in the fluctuating field as well as fluctuations in velocity caused by the turbulent nature of the flow. 


\section{Instantaneous. velocity}

Figure 5 shows the time evolution of the velocity field during an inert gas compression. It is observed $10 \mathrm{~ms}$ BTDC a laminar one-dimensional compression flow. A zone of high velocities ( 5 to $8 \mathrm{~m} / \mathrm{s}$ ), where the flow is turbulent, that come in the center of the clearance volume $5 \mathrm{~ms}$ after. The laminar flow of this zone becomes two-dimensional and diverging to the walls. The turbulent zone reaches TDC and occupies a large part of the chamber at that moment. The flow in this zone is structured by two counter-rotating vortices, which is consistent with the literature where the movement of the piston brings the gas from the side wall toward the center of the chamber, forming vortices on the corners. These vortices then move to the side walls and after down the chamber. Simultaneously, the maximum velocity of the flow gradually decreases, and the size of the 'laminar' zone observed at the end of compression decreases. The disappearance of this zone occurs approximately $17 \mathrm{~ms}$ after TDC, although some low velocity zones remain. $40 \mathrm{~ms}$ after TDC, the corner vortices are replaced by a fragmented and highly three-dimensional flow.

The coexistence of laminar and turbulent regions is characteristic of MCR flat piston flow, where the gases are at rest before compression. One can observe a certain asymmetry in vortices velocity, with lower values at TDC and close to the walls (figure 5). This asymmetry reflects the exchange of kinetic energy that occurs in the strain layer between the vortex and the zone of lower flow. The velocity gradient direction at the zone interface may also be parallel to the mean flow, as is in the case of few milliseconds before TDC. In this case, if the inertia of the high speed zone regrowth clearly the core zone, the turbulent nature of the
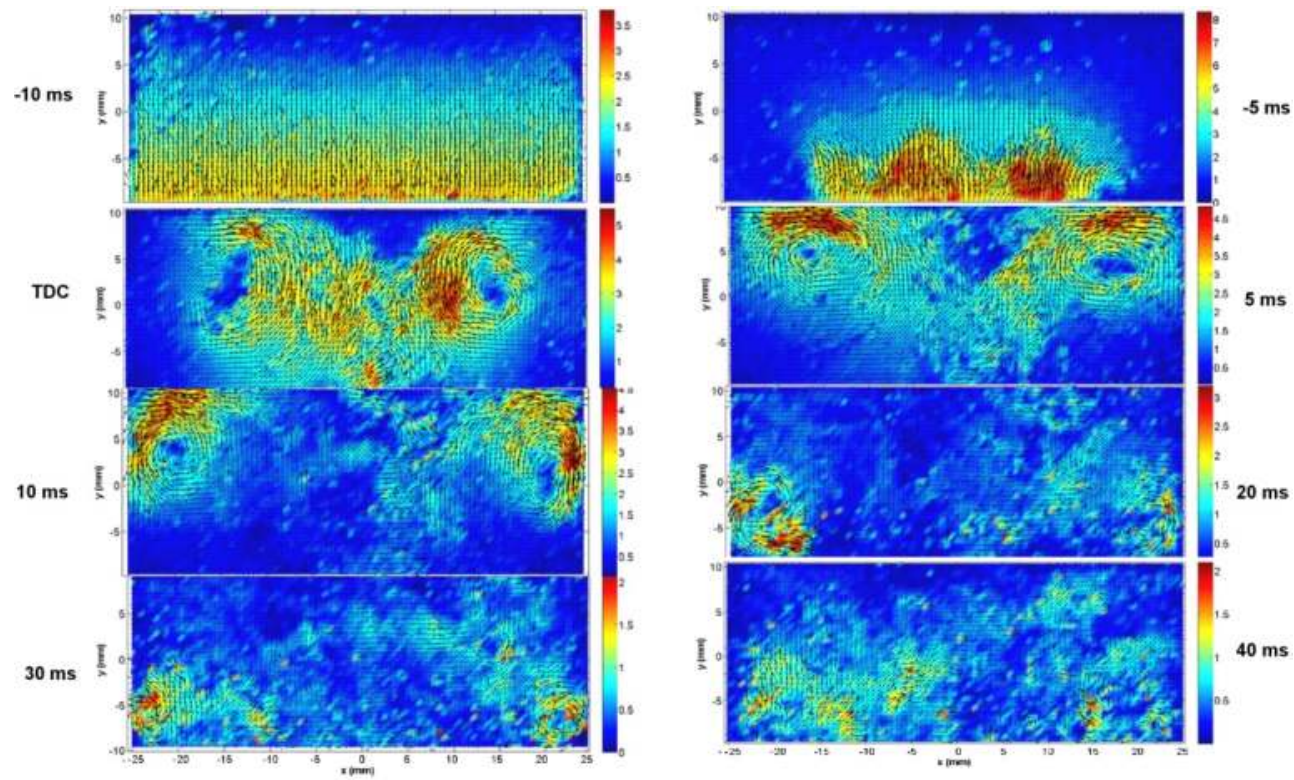

Figure 5. Inert compression velocity fields (m/s) in the RCM [15]. 
flow at the interface is also likely to accelerate the decrease in the extent of the core zone. This emphasis the existence of two ranges of scales associated with mixing phenomenon: those of the overall movement, and those of turbulence. Moreover, the overall velocity of the movement decreases rapidly if the flow stops. Thus, reflecting the kinetic energy transfer from large scales to the turbulent scales.

\subsubsection{Analysis of the flow at the chamber core}

The whole movement has been analyzed, and an initial assessment of turbulent fluctuations was provided from the whole filed measurements. Specific field measurements are now exposed to evaluate the properties of turbulence in detail. The turbulent characteristics are evaluated thanks to particle image velocimetry (PIV) measurements with time resolution of $5 \mathrm{kHz}$ along one field of $13 \times 13 \mathrm{~mm}$ and image resolution of $512 \times 512$ pixels. The investigated zone is close to the center of the chamber $(1.5 \mathrm{~mm}$ to the left), where the mean and fluctuating velocities remain relatively high along a $10 \mathrm{~ms}$ period after TDC. Figure 6 shows the fluctuation velocity components in this zone. It is observed that both velocity components fluctuations decrease after TDC with similar amplitude. The maximum of flow velocity is obtained $2-3 \mathrm{~ms}$ before TDC with values around $0.65 \mathrm{~m} / \mathrm{s}$. It is followed by a rapid decrease to around $0.4 \mathrm{~m} / \mathrm{s}$ that reflect the overall decrease of the convection of the fastest zones outside the measured field.

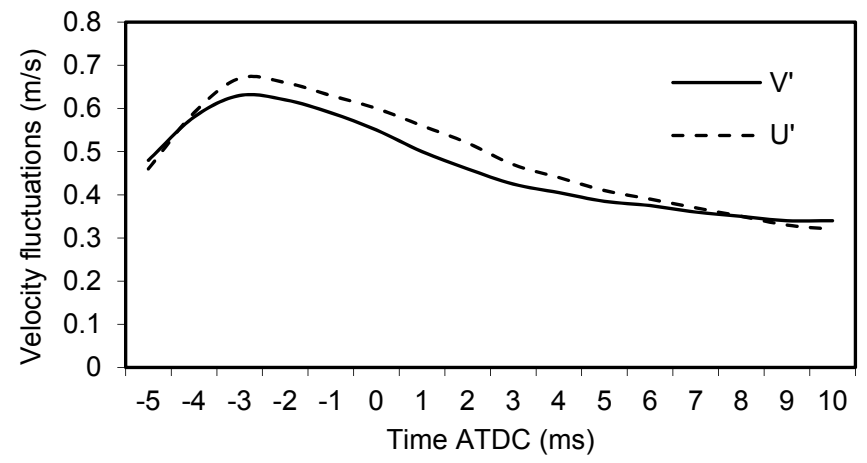

Figure 6. Time evolution of the variation of velocity fluctuations [15].

Both velocity components fluctuations decrease after TDC with similar amplitude. The kinetic energy $(k)$ is evaluated only from two velocity components $(u, v)$ as follows:

$$
k=\sqrt{u^{2}+v^{2}}
$$

It is therefore, slightly underestimated ( $20 \%)$ due to the lack of the third component. The turbulent intensity $I$ obtained by:

$$
I=\frac{u^{\prime}}{U}
$$


Where $\mathrm{u}^{\prime}$ is the root mean square (rms) of the turbulent velocity fluctuations and $U$ the mean velocity (Reynolds averaged).

Figure 7 represents the kinetic turbulent energy. The maximum of kinetic energy is obtained 2-3 ms before TDC. It is followed by a rapid decrease that reflects both the overall decrease of the turbulent kinetic energy but also the convection of the fastest zones outside the measured field.
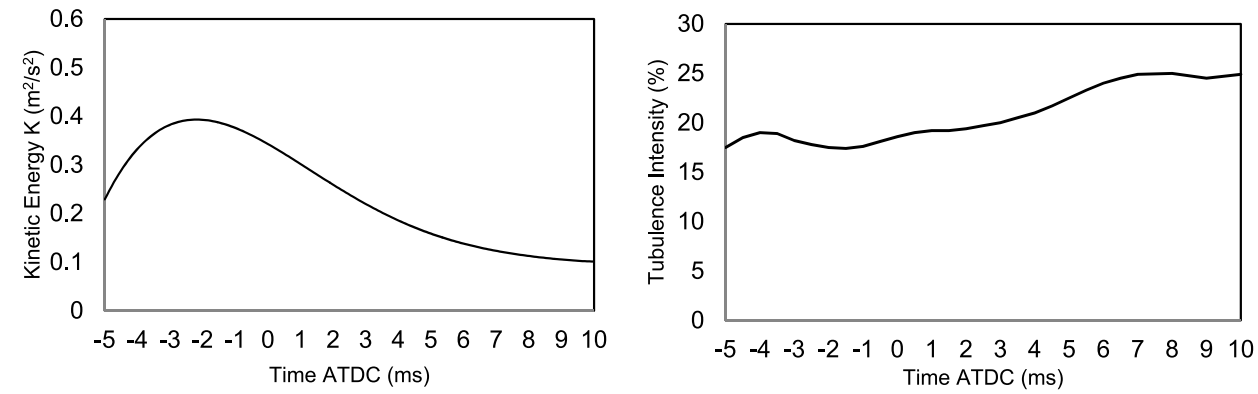

Figure 7. Kinetic energy (left) and turbulence intensity (right) [15].

The turbulent intensity is moderate, with a value of about $20 \%$ with minor variations over time. One should remind that this value corresponds to a high velocity turbulent zone.

\section{Results and discussion}

The RCM can work on two distinctive modes: single compression stroke and compression and expansion strokes.

Single compression is generally used for the study of high pressure auto-ignition of combustible mixtures as it gives direct measure of ignition delay [11]. When the interest is the heat transfer to the walls then it is usually used an inert gas, with equal adiabatic coefficient as the reacting mixture, as a test gas. In this work instead of an inert gas a stoichiometric syngas-air mixture was used out of auto-ignition conditions in order to provide data for the thermal model simulation.

Compression and expansion strokes simulate a single engine cycle of an internal combustion engine under easily controlled conditions and a cleaner environment than the traditional internal combustion engine.

\subsection{Single compression}

Figures 8-9 show RCM experimental pressure histories of stoichiometric syngas-air mixtures for various spark times and compression ratio $\varepsilon=11$. Four ignition timings were tested: TDC, and 5.0, 7.5 and $12.5 \mathrm{~ms}$ before TDC, respectively. 


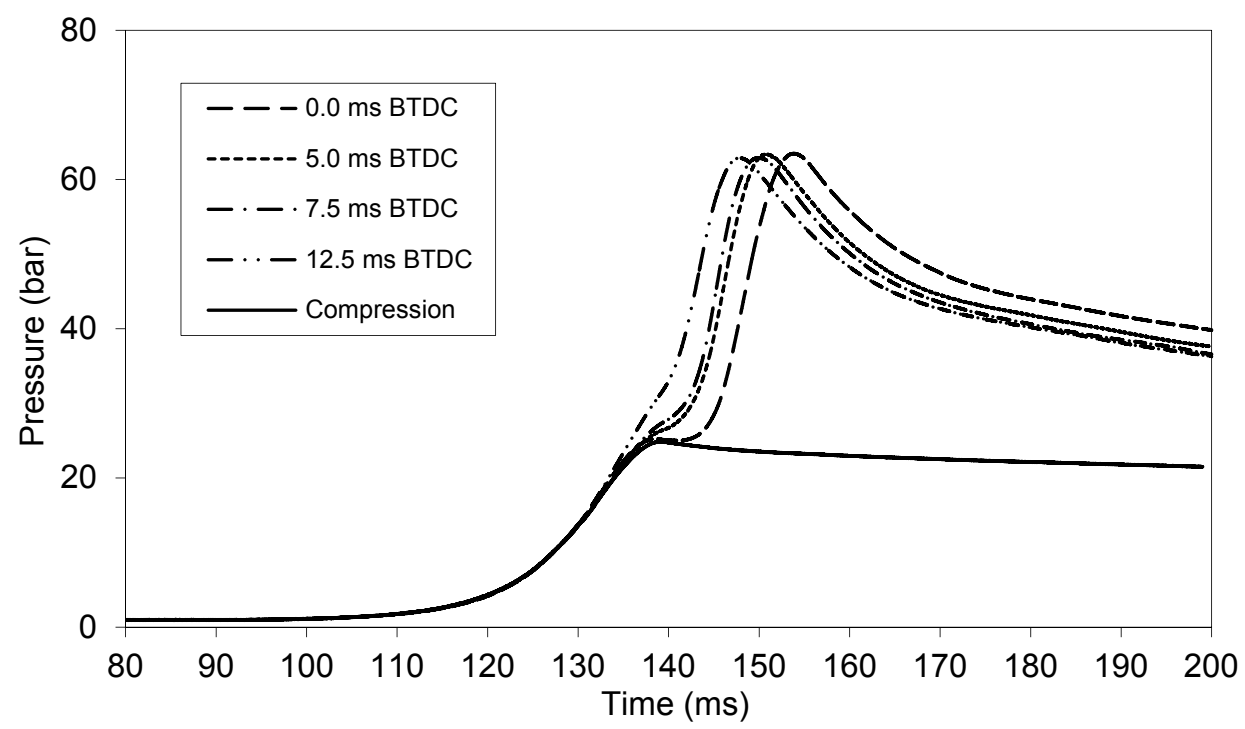

Figure 8. Pressure versus time for stoichiometric updraft syngas-air mixture at various spark times.

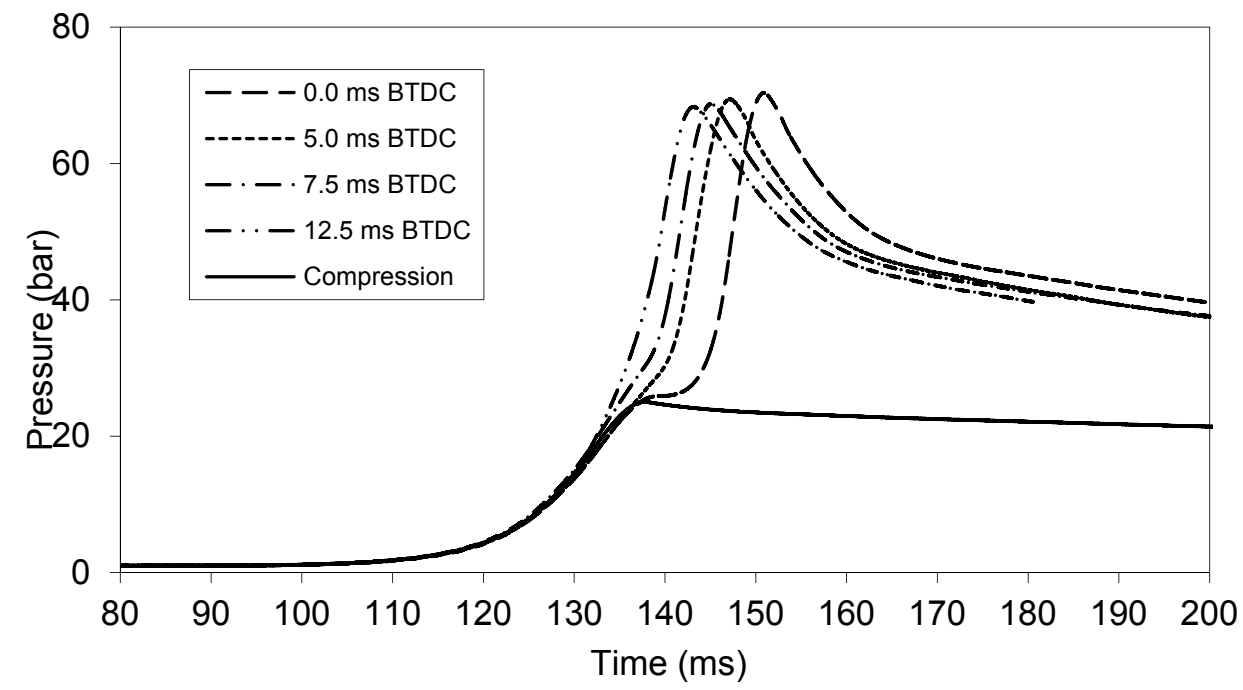

Figure 9. Pressure versus time for stoichiometric downdraft syngas-air mixture at various spark times.

In both syngas cases, peak pressure decreases as the ignition time increases. When ignition is made at TDC, combustion will occur at constant volume, in the clearance volume. In this case, one has higher initial pressure and temperature and no influence of the flow of the fresh mixture being compressed by the piston movement, which reduces turbulence and, in turns, the heat transfer. As far as ignition timing concerns, the deviation from TDC allows 
lower initial pressure and temperature for combustion in the compression stroke and consequently lower peak pressure. It is also observed a reduction in the pressure gradient after TDC, which means that the heat released by combustion of syngas-air mixtures is not enough to keep the same pressure gradient. One can observe that the pressure gradient is kept for ignition timing of $12.5 \mathrm{~ms}$ BTDC.

As mentioned above, experiments with stoichiometric methane-air mixture were also performed for comparison reasons and the results are shown in Fig. 10.

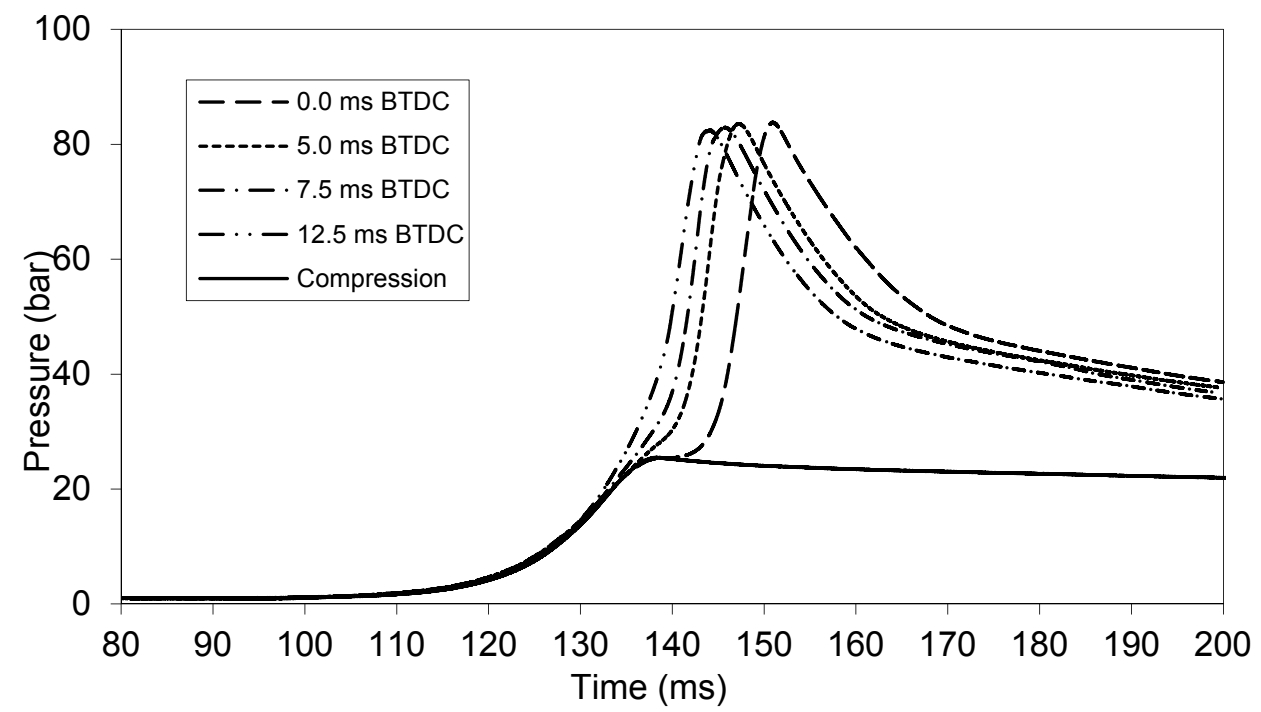

Figure 10. Pressure versus time for stoichiometric methane-air mixture at various spark times.

This mixture follows the same behaviour of the typical syngas compositions nevertheless with higher pressures. For these results contributes the fact that the syngas stoichiometric air-fuel ratio ranges between 1.0 (downdraft) and 1.12 (updraft) compared with the value of 9.52 for methane. Taking into account that the RCM chamber has 1.0 Liter, the energy introduced in to the chamber is $2.60 \mathrm{~kJ}$ in the updraft case, $2.85 \mathrm{~kJ}$ in the downdraft case and $3.38 \mathrm{~kJ}$ in the methane case for stoichiometric conditions. These values are in agreement with the obtained cylinder pressures, however not proportional in terms of peak pressures due to the influence of heat losses. These are mainly dependent of the quenching distance as well as thermal conductivity of the mixture. The higher burning velocity of methane (see Ref. [24]) compared to syngas compositions also cause a more intensified convection.

\subsubsection{Direct light visualization from chemiluminescence emission}

Direct visualizations of the flame propagation in a RCM are shown in Fig. 11 for updraft syngas and for ignition at TDC and $12.5 \mathrm{~ms}$ BTDC, to clearly establish differences. 


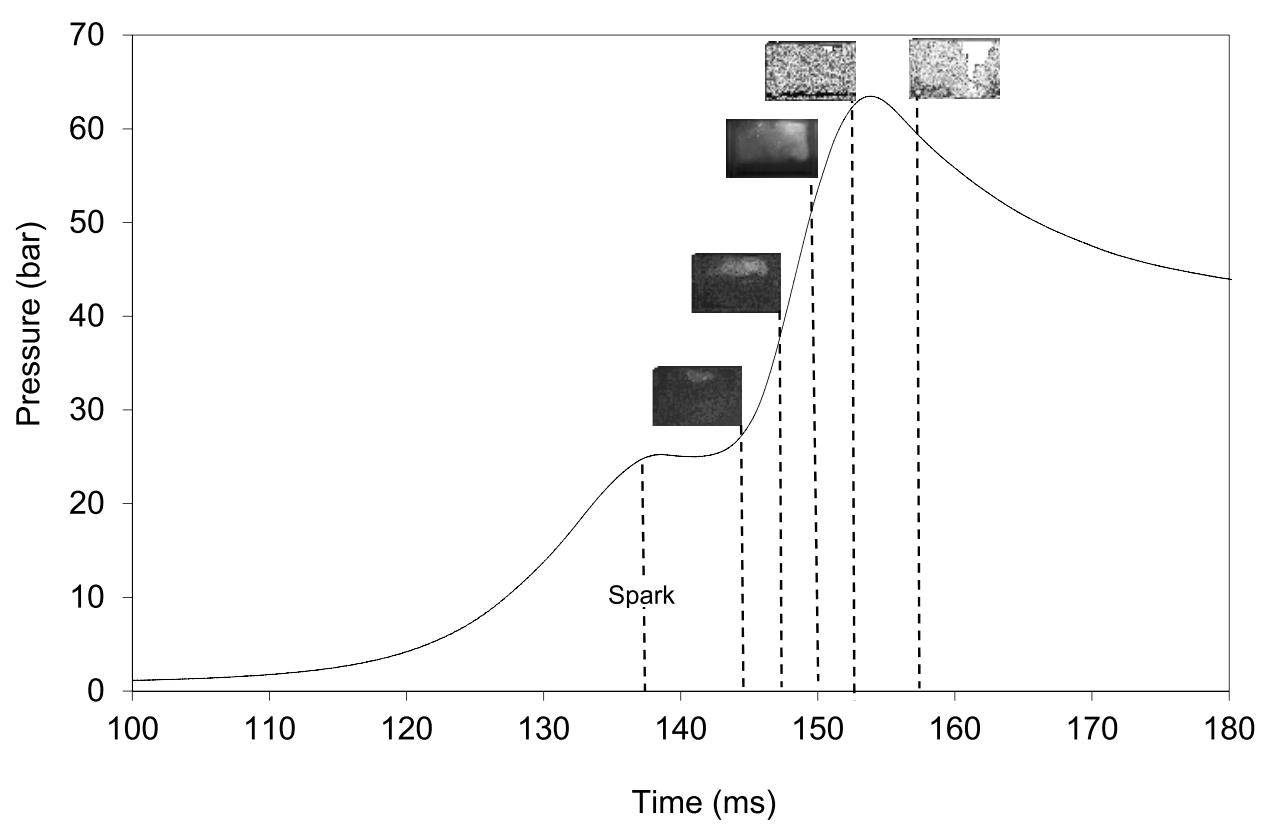

(a)

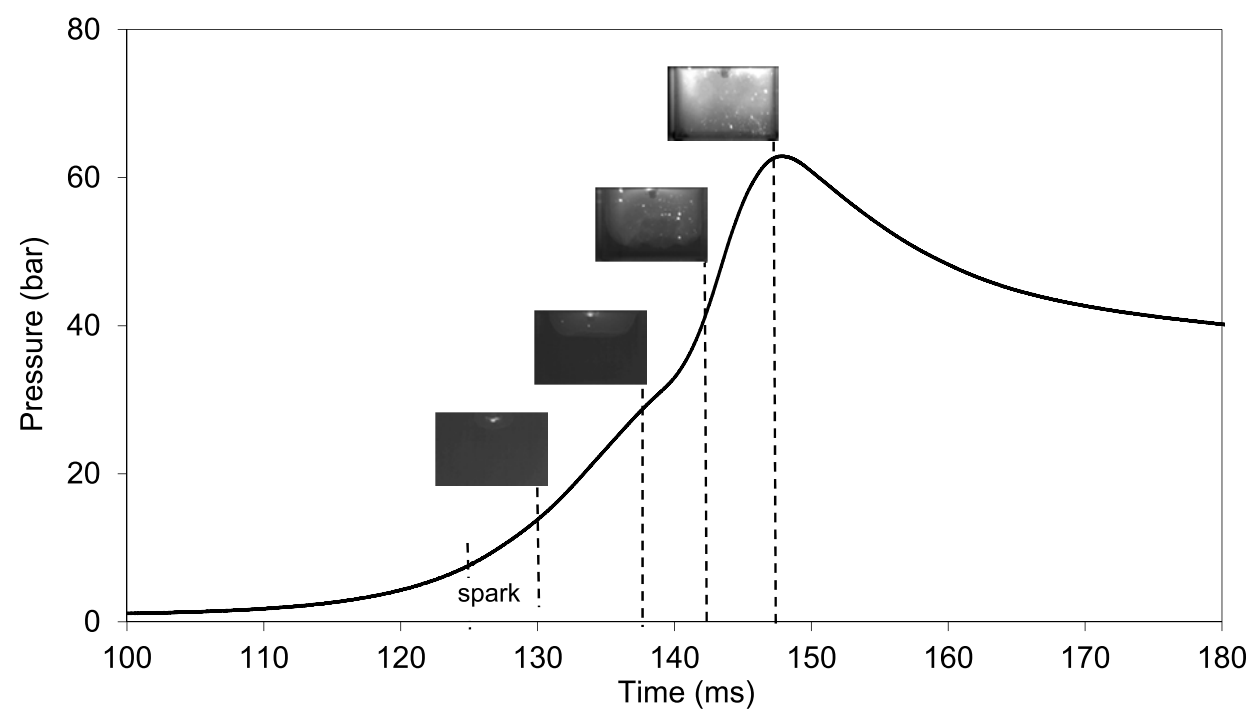

(b)

Figure 11. Direct visualization of stoichiometric updraft syngas-air mixtures combustion in a RCM. (a) Ignition at TDC; (b) Ignition at $12.5 \mathrm{~ms}$ BTDC [25]. 
When the ignition is made at TDC the combustion occurs at constant volume, in the clearance volume. Direct visualizations show an explosion with fast and turbulent flame propagation with combustion duration of about $17.5 \mathrm{~ms}$. In opposite, the initial phase of combustion shows a quasi-spherical relatively smooth flame kernel specially for ignition timing of $12.5 \mathrm{~ms}$ BTDC. The flame kernel propagation is laminar and at some point experience flattening due to piston movement reaching the TDC. After that, a change to constant volume combustion occurs. The whole combustion duration is around $22.5 \mathrm{~ms}$, which represents a remarkable increase compared with the full constant volume combustion. The deviation of the spark plug from TDC allows lower initial pressure and temperature for combustion in the compression stroke and lower turbulence intensity [12].

\subsection{Compression -expansion}

Figures 12-14 show RCM experimental pressure histories of stoichiometric syngas-air mixtures and methane-air for various spark times and compression ratio $\varepsilon=11$. The ignition timings tested were $5.0 \mathrm{~ms}, 7.5 \mathrm{~ms}$ and $12.5 \mathrm{~ms}$ BTDC.

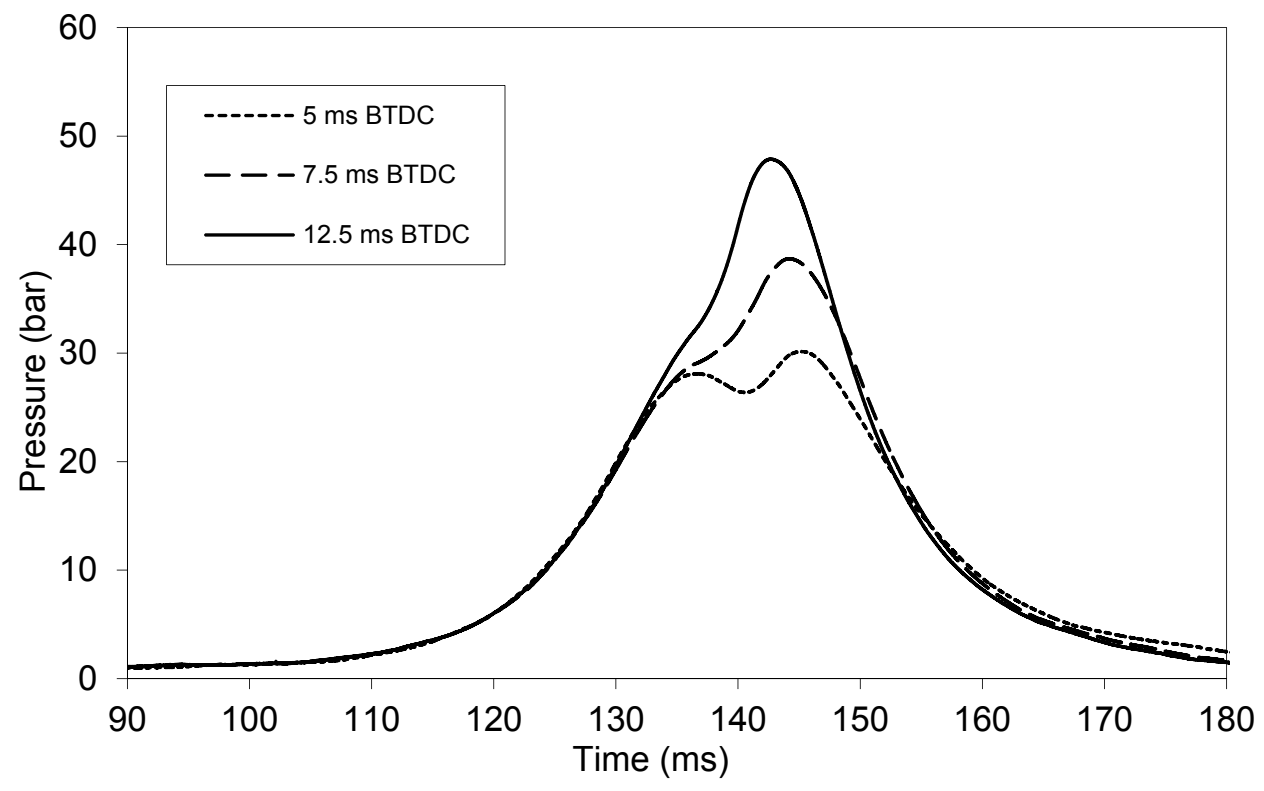

Figure 12. Pressure versus time for stoichiometric updraft syngas-air mixture at various spark times. 


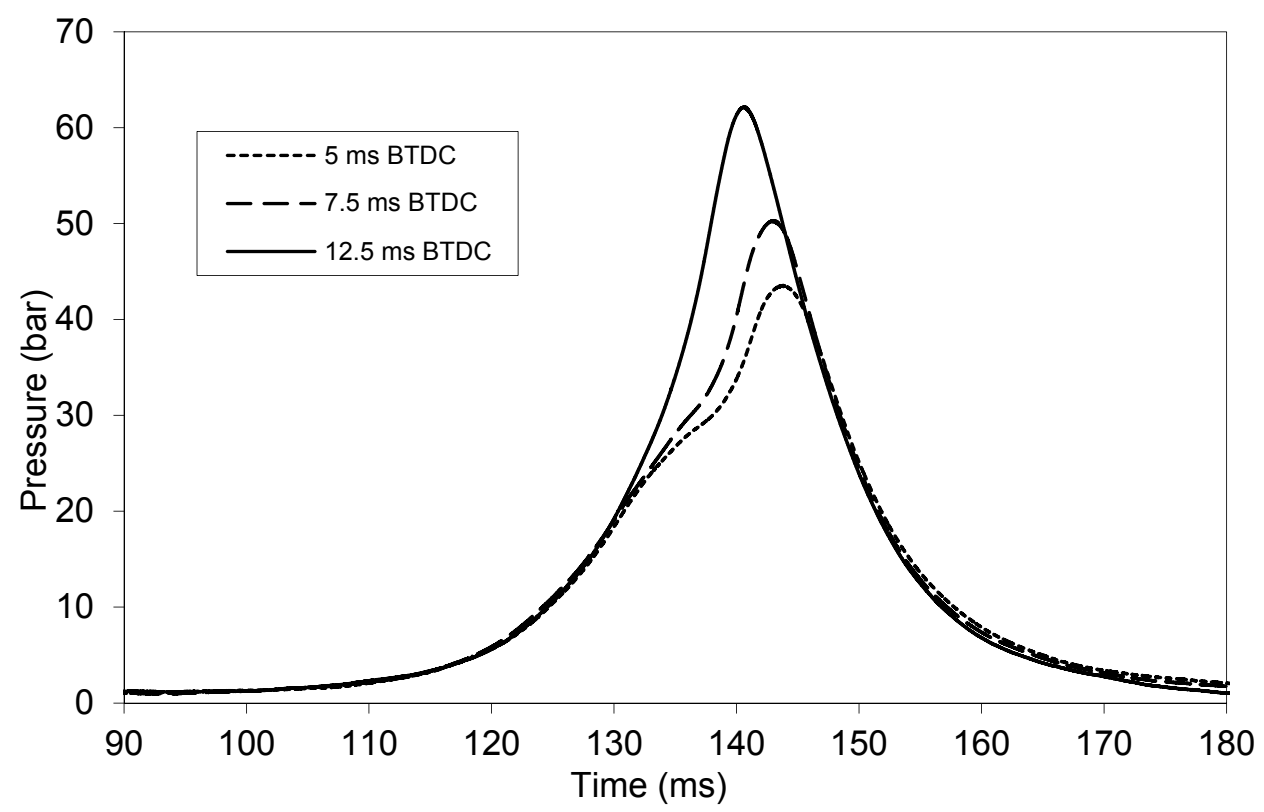

Figure 13. Pressure versus time for stoichiometric downdraft syngas-air mixture at various spark times.

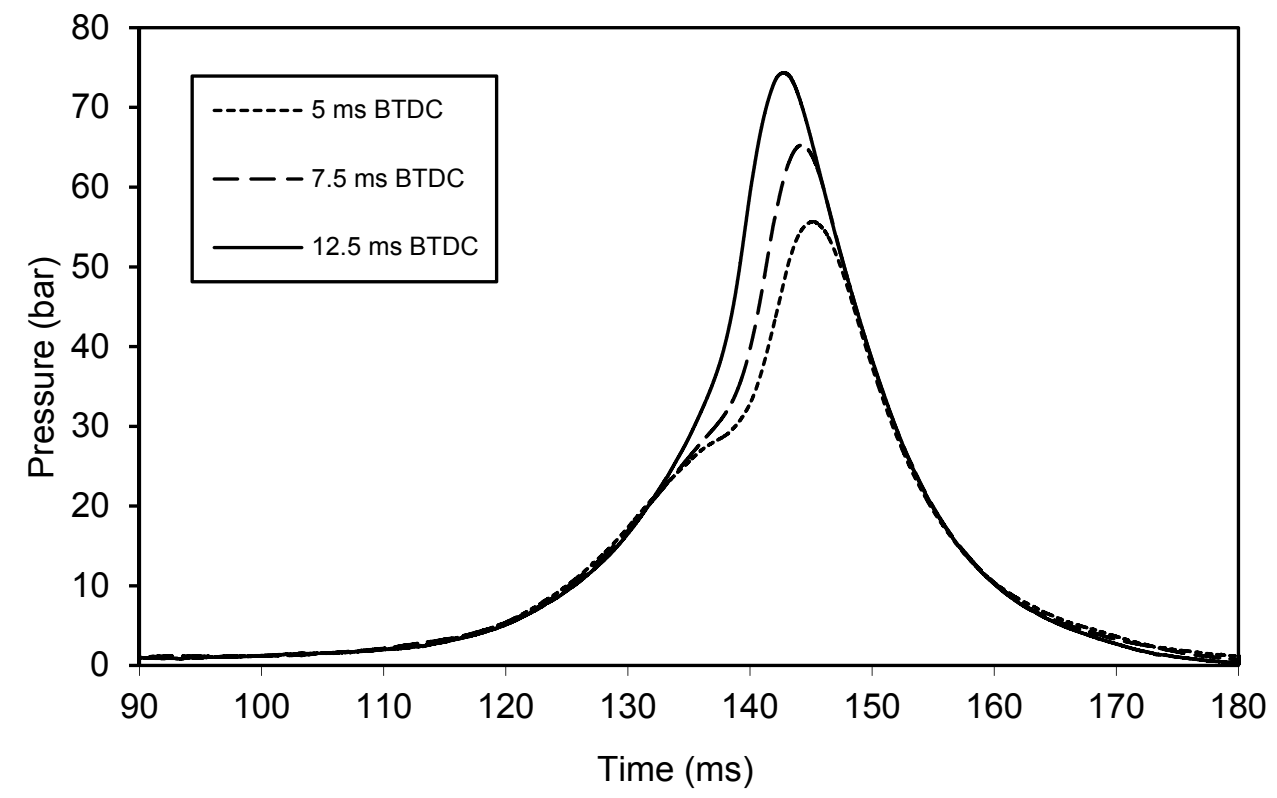

Figure 14. Pressure versus time for stoichiometric methane-air mixture at various spark times. 
From Figs. 12-14 it is observed that the in-cylinder pressure increases as the spark time deviates from TDC. If combustion starts too early in the cycle, the work transfer from the piston to the gases in the cylinder at the end of the compression stroke is too large. If the combustion starts too late, the peak cylinder pressure is reduced, and the stroke work transfer from the gas to the piston decreases. Another observation that is brought out from these figures is that higher pressures are obtained with methane-air mixture followed by downdraft syngas-air mixture and lastly by updraft syngas-air mixture, which represents the same behavior observed in the single compression case.

Making a parallel with the laminar combustion case where the performances of updraft and downdraft syngas are similar (see Ref. [24]). This behaviour is not found in turbulent conditions, where peak pressure of downdraft syngas is higher in about $25 \%$. As the turbulent burning velocity could be considered as proportional to the laminar one [26], the correlations (Eq. 5, 6) shows that the laminar burning velocity increases with temperature increase and decreases with the increase of pressure. Temperature is irrelevant in this comparison since the temperature coefficient is similar for both syngas compositions. However, pressure coefficient for updraft syngas is $40 \%$ higher in relation to downdraft syngas coefficient. This means that the higher pressures used on the RCM have a higher impact in reducing the laminar burning of updraft syngas composition and, thus, justifying the lower pressures obtained in turbulent conditions.

\subsubsection{Direct light visualization from chemiluminscence emission}

Burning of a mixture in a cylinder of a SI engine may be divided into the following phases: (1) spark ignition, (2) laminar flame kernel growth and transition to turbulent combustion,

(3) turbulent flame development and propagation, (4) near-wall combustion and after burning. Figures 15-17 show flame propagation images of stoichiometric syngas-air mixtures combustion and stoichiometric methane-air mixtures in a RCM, where is possible to observe these first three phases of combustion and the corresponding pressure.

In these figures, after the passage of spark, there is a point at which the beginning of pressure rise can be detected. This stage is referred to as ignition lag or preparation phase in which growth and development of a self propagating nucleus of flame takes place. This is a chemical process depending upon both pressure and temperature and the nature of the fuel. Therefore, this stage is longer for earlier ignition timings as shown in the figures 15-17. Pictures of this initial phase of combustion show an initially quasi-spherical, relatively smooth flame kernel for syngas compositions and methane.

After this stage and up to the attaining of peak pressure another stage of combustion could be considered as second stage. This is a physical one and is concerned with the spread of the flame throughout the combustion chamber. The starting point of the second stage is where the first measurable rise of pressure is seen, i.e. the point where the line of combustion departs from the compression (motoring) line. This can be seen from the deviation from the 


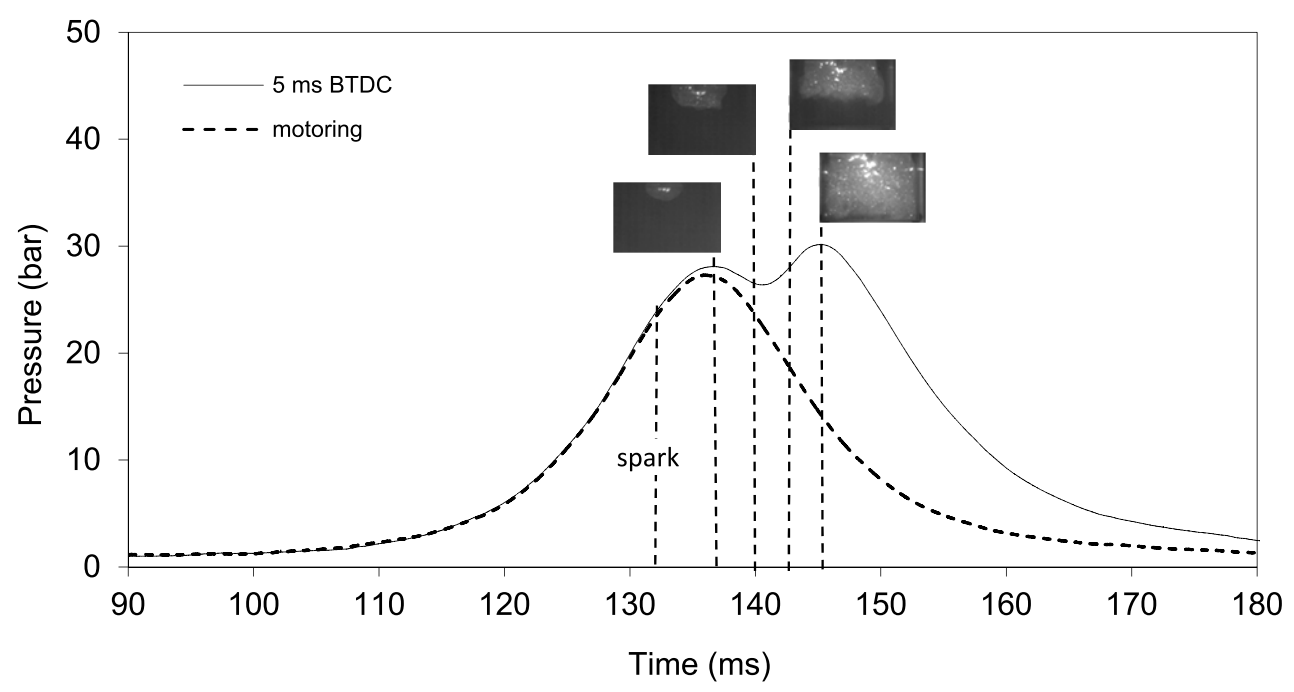

(a)

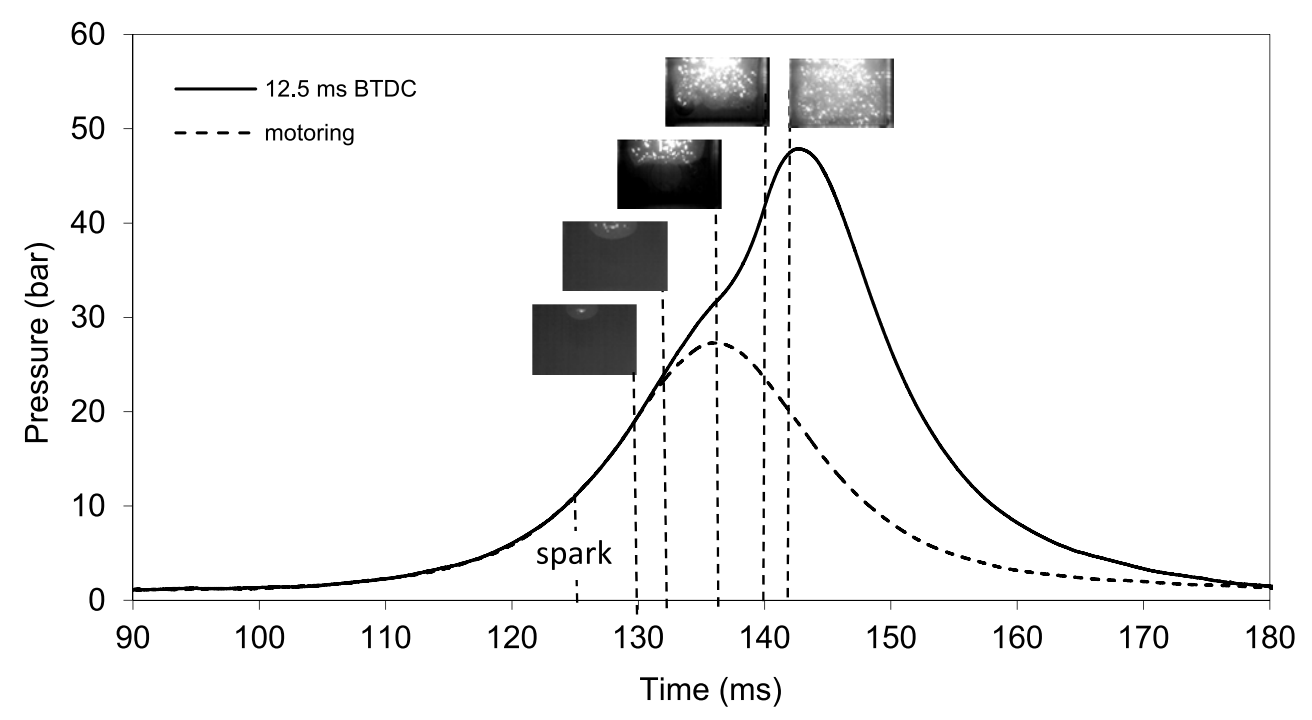

(b)

Figure 15. Direct visualization of stoichiometric updraft syngas-air flame in a RCM for various Ignition timings. (a) 5 ms BTDC; (b) 12.5 ms BTDC [25] 


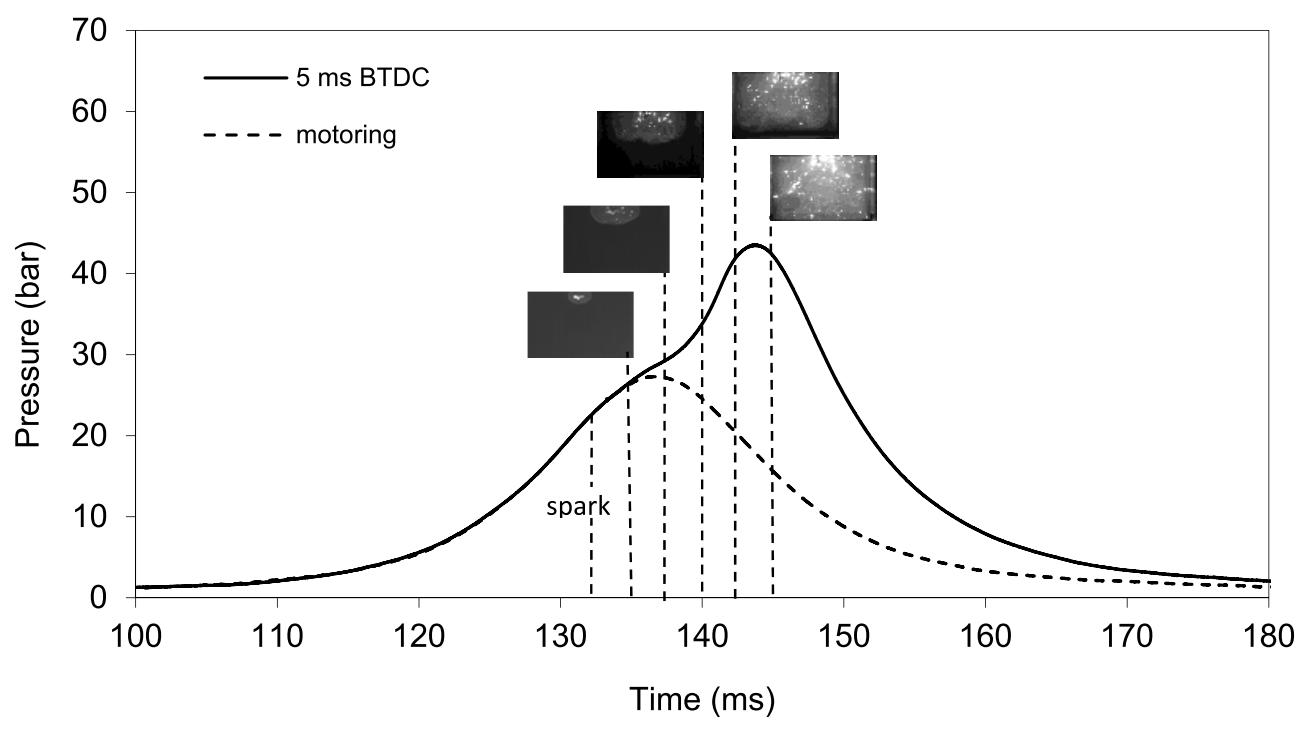

(a)

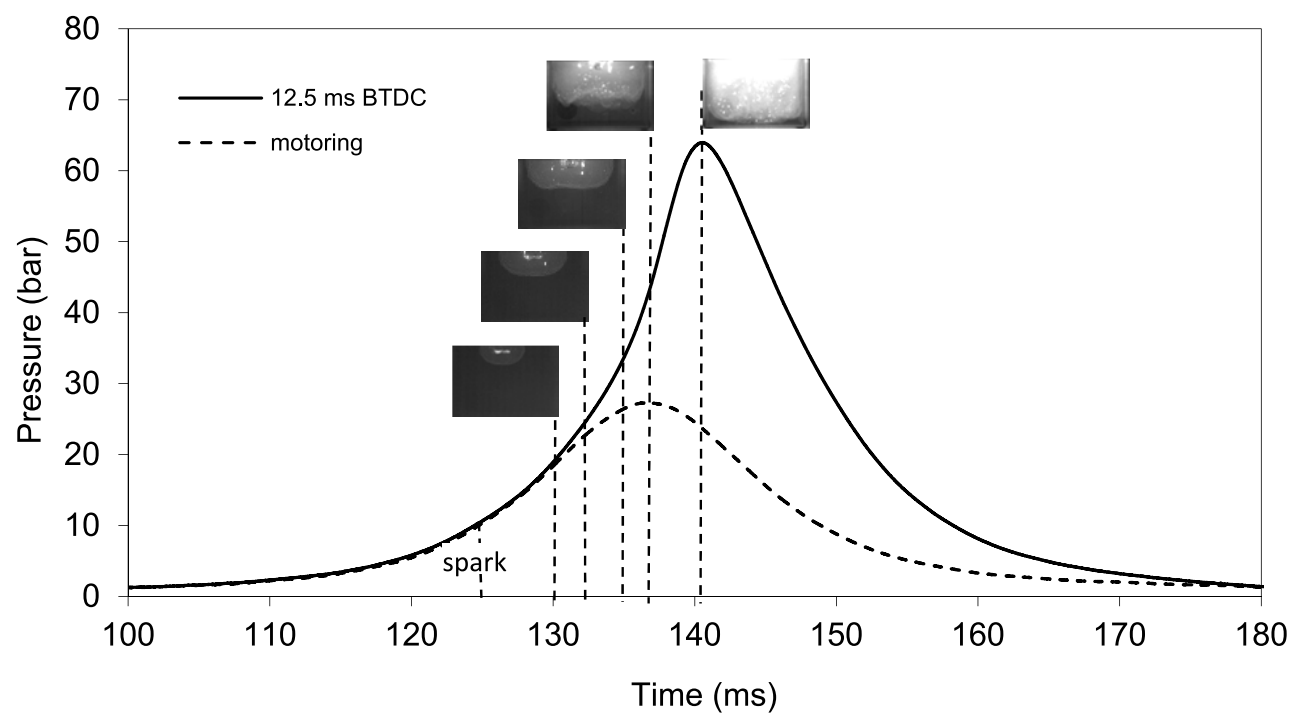

(b)

Figure 16. Direct visualization of stoichiometric downdraft syngas-air flame in a RCM for various Ignition timings. (a) 5 ms BTDC; (b) 12.5 ms BTDC [25]. 


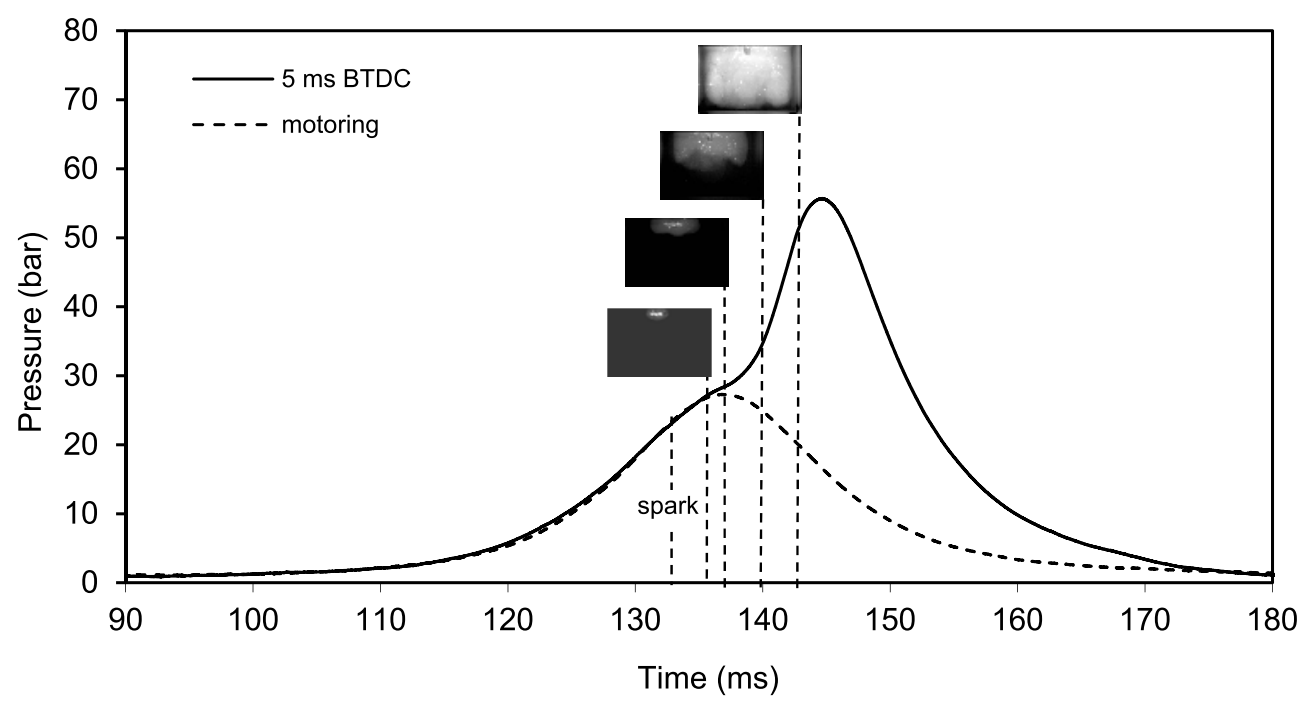

(a)

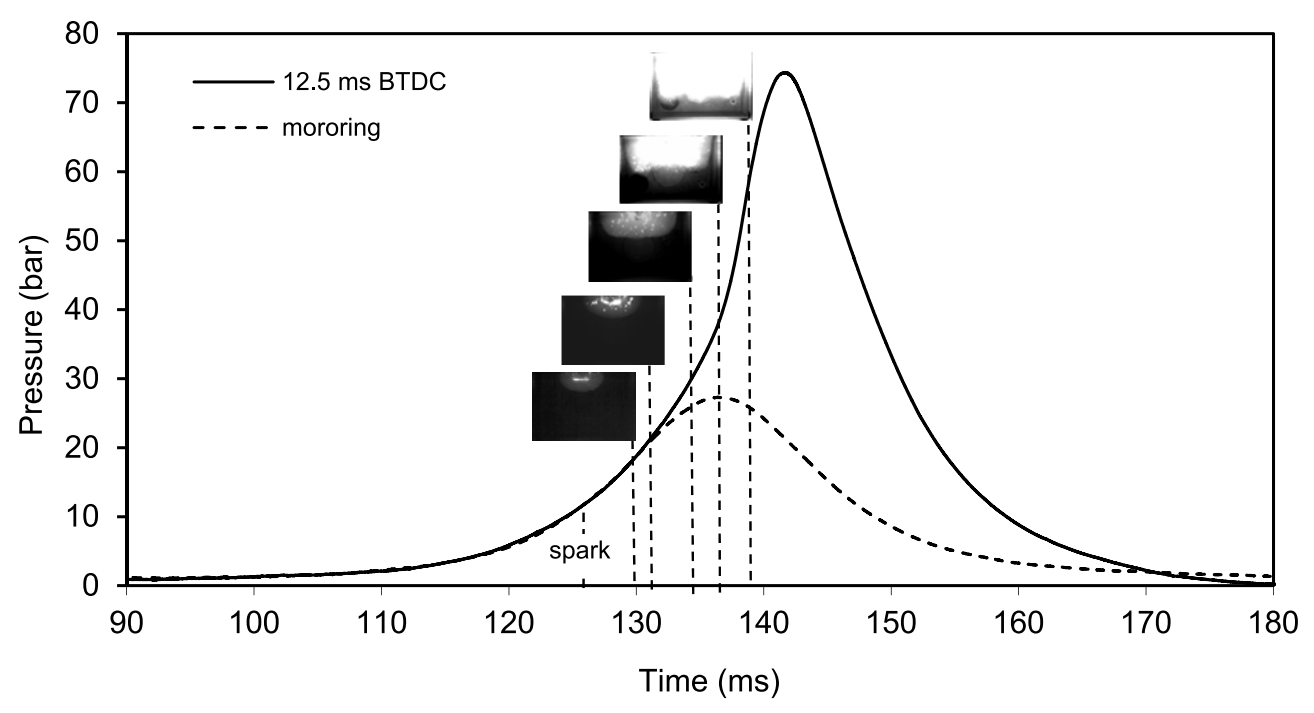

(b)

Figure 17. Direct visualization of stoichiometric methane-air flame in a RCM for various Ignition timings. (a) 5 ms BTDC; (b) $12.5 \mathrm{~ms}$ BTDC [25]. 
motoring curve. During the second stage the flame propagates practically at a constant velocity. Heat transfer to the cylinder wall is low, because only a small part of the burning mixture comes in contact with the cylinder wall during this period. The rate of heat release depends largely of the turbulence intensity and also of the reaction rate which is dependent on the mixture composition [27]. The rate of pressure rise is proportional to the rate of heat release because during this stage, the combustion chamber volume remains practically constant (since the piston is near the TDC where the turbulence intensity is higher [15]). Therefore, comparing the three fuels, it is observed that this stage of combustion is faster for methane, followed by downdraft syngas and finally by updraft syngas. This behavior is in agreement with the heat of reaction of the mixtures as well as with the laminar burning velocity of typical syngas compositions.

The starting point of the third stage is usually taken at the instant at which the maximum pressure is reached. The rate of combustion becomes low due to lower flame velocity and reduced flame front surface. Direct flame visualizations of this stage are not shown in the figures 15-17 because the combustion continues in the expansion stroke, i.e. away from the clearance volume. Since the expansion stroke starts before this stage of combustion, with the piston moving away from the TDC, there can be no pressure rise during this stage.

\subsubsection{Ignition timing}

Timing advance is required because it takes time to burn the air-fuel mixture. Igniting the mixture before the piston reaches TDC will allow the mixture to fully burn soon after the piston reaches TDC. If the air-fuel mixture is ignited at the correct time, maximum pressure

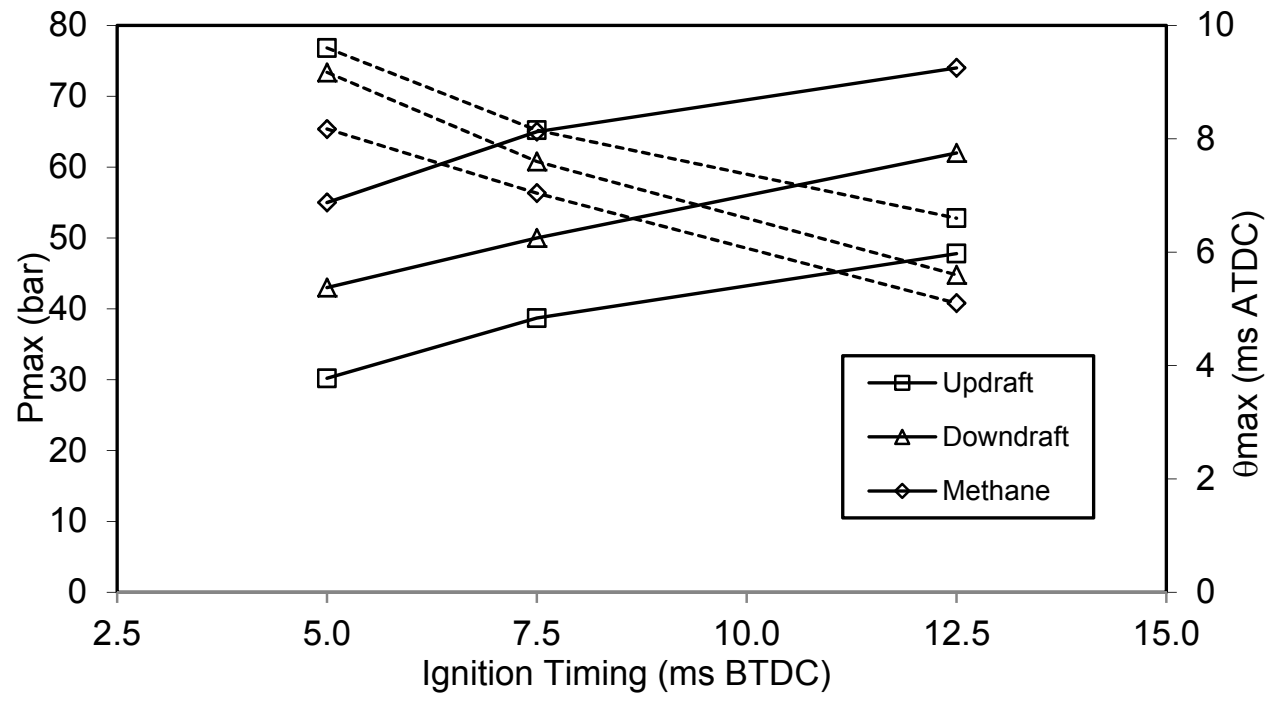

Figure 18. Pressure peak (continuous lines) and pressure peak position (dashed lines) versus ignition timing for stoichiometric syngas-air and methane-air mixtures. 
in the cylinder will occur sometime after the piston reaches TDC allowing the ignited mixture to push the piston down the cylinder. Ideally, the time at which the mixture should be fully burned is about $20^{\circ}$ ATDC [28]. This will utilize the engine power producing potential. If the ignition spark occurs at a position that is too advanced relative to piston position, the rapidly expanding air-fuel mixture can actually push against the piston still moving up, causing detonation and lost power. If the spark occurs too retarded relative to the piston position, maximum cylinder pressure will occur after the piston is already traveling too far down the cylinder. This results in lost power, high emissions, and unburned fuel. In order to better analyze these experimental results, Fig. 18 synthesizes the peak pressure $P_{\max }$, and the position of peak pressure $\theta_{\max }$ expressed in milliseconds ATDC for the variable ignition timing in milliseconds BTDC.

From Fig. 18 it is clear that the in-cylinder pressure increases as the ignition timing is retarded. The pressure peak occurs latter as the ignition timing decreases. In opposite to static chamber combustion, the peak pressure does not represent the end of combustion. However, is possible to conclude that the peak pressure occurs always after TDC.

\section{Conclusion}

The syngas application to spark ignition engine by the use of rapid compression machine is made experimentally. There is an opposite behavior of the in-cylinder pressure between single compression and compression and expansion strokes. The first is that one gets higher in-cylinder pressures on single compression event than for compression-expansion events, which emphasis the fact of the constant volume combustion to be the way of getting higher pressures. The second is that for single compression peak pressure decreases as the ignition delay increases. In opposite, for compression-expansion the peak pressure increases with the ignition delay increase. This opposite behaviour has to do with the deviation of the spark plug from TDC position that influences the combustion duration in the compression stroke and this extent has different consequences on peak pressure regarding the number of strokes events. For single compression it reduces the constant volume combustion duration. For compression-expansion strokes it increases the combustion duration on the compression stroke where the heat released has the effect of generate pressure before expansion. In both experimental events, higher pressures are obtained with methane-air mixture followed by downdraft-syngas and lastly by updraft-syngas. These results could be endorsed to the heat of reaction of the fuels, air to fuel ratio and also to burning velocity. Crossing the heat value with the air to fuel ratio conclusion could be drawn that the energy content inside the combustion chamber is in agreement, however not proportional with the obtained pressures. Updraft and downdraft syngas compositions have similar burning velocities on laminar conditions (see Ref. [16, 24]) but the same is not found in turbulent conditions, where the difference on pressure peak is higher in about $25 \%$. As the turbulent burning velocity is proportional to the laminar burning velocity, the analysis of the correlations for laminar burning velocity of typical syngas compositions shows that the effect of pressure is very significant (pressure coefficient for updraft syngas is $40 \%$ higher in relation to downdraft syngas coefficient). The higher pressure used on RCM also makes temperature to 
increase due to compression but the effect of temperature on burning velocity for typical syngas compositions is irrelevant since the temperature coefficient is of the same order. Another major finding is that syngas typical compositions are characterized by high ignition timings due to its low burning velocities.

\section{Author details}

Eliseu Monteiro and Abel Rouboa

CITAB, University of Trás-os-Montes and Alto Douro, Vila Real, Portugal

Marc Bellenoue and Julien Sottton

Institute $P^{\prime}$, ENSMA, CRNS, 86961, Futuroscope Chasseneuil Cedex, France

\section{Acknowledgement}

This work is supported by European Union Funds (FEDER/COMPETE - Operational Competitiveness Programme) and by national funds (FCT - Portuguese Foundation for Science and Technology) under the project FCOMP-01-0124-FEDER-022696.

This work was made on behalf of the FCT (Portuguese Foundation for Science and Technology) project PTDC/AAC-AMB/103119/2008.

\section{References}

[1] International energy agency. world energy outlook 2000, IEA, Paris, 2000.

[2] IEA bioenergy. The role of bioenergy in greenhouse gas mitigation. Position paper. IEA Bioenergy, New Zealand, 1998.

[3] A.V. Bridgwater, The technical and economic feasibility of biomass gasification for power generation, Fuel 14 (5) (1995) 631-653.

[4] C.D Rakopoulus, C.N. Michos, Development and validation of a multi-zone combustion model for performance and nitric oxide formation in syngas fueled spark ignition engine, Energy Conversion and Management, 49 (10) (2008) 2924-2938.

[5] C.R. Stone, N. Ladommatos, Design and evaluation of a fast-burn spark-ignition combustion system for gaseous fuels at high compression ratios, Journal of the Institute of Energy 64 (1991) 202-211.

[6] Li H., G.A. Karim, Experimental investigation of the knock and combustion characteristics of $\mathrm{CH} 4, \mathrm{H} 2, \mathrm{CO}$, and some of their mixtures, Proceedings of the Institution of Mechanical Engineers, Part A: Journal of Power and Energy 220 (2006) 459-471.

[7] S. Rosseau, B. Lemoult, M. Tazerout, Combustion characterization of natural gas in a lean burn spark-ignition engine, Proceedings of the Institution of Mechanical Engineers, Part D: Journal of Automobile Engineering 213 (1999) 481-489.

[8] Heywood J.B., Internal combustion engine fundamentals, McGraw-Hill, New York, 1988.

[9] G. Sridhar, P.J. Paul, H.S. Mukunda, Biomass derived producer gas as a reciprocating engine fuel-an experimental analysis, Biomass Bioenergy 21 (2001) 61-72. 
[10] C. Strozzi, J. Sotton, A. Mura, M. Bellenoue, Experimental and numerical study of the influence of temperature heterogeneities on self-ignition process of methane-air mixtures in a rapid compression machine, Combustion Science and Technology 180 (2008) 1829-1857.

[11] J.F. Griffiths, J.P. MacNamara, C.G.W. Sheppard, D.A.Turton, B.J. Whitaker, The relationship of knock during controlled autoignition to temperature in homogeneities and fuel reactivity, Fuel 81 (7) (2002) 2219-2225.

[12] S.M. Walton, X. He, B.T. Zigler, M.S. Wooldridge, A. Atreya, An experimental investigation of iso-octane ignition phenomena, Combust. Flame 150 (3) (2007) 246-262.

[13] G. Cho, G. Moon, D. Jeong, C. Bae, Effects of internal exhaust gas recirculation on controlled auto-ignition in a methane engine combustion, Fuel 88 (6) (2009) 1042-1048.

[14] G. Mittall, C.J. Sung, A rapid compression machine for chemical kinetics studies at elevated pressures and temperatures, Combust. Sci. Technol. 179 (2007) 497-530.

[15] C. Strozzi, Étude expérimentale de l'auto-inflammation de mélanges gazeux en milieux confines et sa modélisation avec une description cinétique chimique détaille, PhD Thesis, University of Poitiers, France, 2008.

[16] Eliseu Monteiro, Combustion study of mixtures resulting from a gasification process of forest biomass. PhD Thesis, ENSMA, France, 2011.

[17] Lewis B., von Elbe G., Combustion, Flames and Explosions of Gases, $3^{\text {rd }}$ Edition, Academic Press, 1987.

[18] Metghalchi, M., and Keck, J. C., Laminar Burning velocity of propane-air mixtures at high temperatures and pressure. Combustion and Flame 38 (1980) 143-154.

[19] Ganesan V. Internal Combustion Engines. McGraw-Hill companies, 1995.

[20] Griffiths J.F, Q. Liao, A. Schreiber, J. Meyer, K.F Knoche, W. Kardylewski. Experimental and numerical studies of ditertiary butyl peroxide combustion at high pressures in a rapid compression machine. Combustion and Flame 93 (1993).303-315.

[21] Clarkson J., Griffiths J.F., Macnamara J.P., Whitaker B.J. Temperature fields during the development of combustion in a rapid compression machine. Combustion and Flame 125 (2001) 1162-1175.

[22] Minetti R., Carlier M., Ribaucour M., E. Therssen, L.R. Sochet. Comparison of oxidation and autoignition of the two primary reference fuels by rapid compression. Proceedings of the Combustion Institute 26 (1996) 747-753.

[23] Liou, T.M., Santavicca, D.A. Cycle resolved LDV measurements in a motored IC engine. Transitions of the ASME. Journal of Fluids Engineering 107 (1985) 232-240.

[24] Eliseu Monteiro, M. Bellenoue, J. Sotton, N.A. Moreira, S. Malheiro, Laminar burning velocities and Markstein numbers of syngas-air mixtures, Fuel 89 (2010) 1985-1991.

[25] Eliseu Monteiro, J. Sotton, M. Bellenoue, N. A. Moreira, S. Malheiro. Experimental study of syngas combustion at engine-like conditions in a rapid compression machine. Experimental Thermal and Fluid Sciences 35 (2011) 1473-1479.

[26] S. Verhelst, R. Sierens, A quasi-dimensional model for power cycle of a hydrogenfuelled ICE, International Journal of Hydrogen Energy 32 (2007) 3545-3554.

[27] Alla A.G.H., Computer simulation of a four stroke spark ignition engine, Energy Conversion and Management 43 (2002) 1043-1061.

[28] J. Hartman, How to Tune and Modify Engine Management Systems, Motorbooks, 2004. 